\title{
Prospecção científica e tecnológica da Tabebuia reseoalba (Ipê-branco)
}

\author{
Scientific and technological prospection of Tabebuia reseoalba (Ipê-branco) \\ Prospección científica y tecnológica de Tabebuia reseoalba (Ipê-branco)
}

Recebido: 10/08/2021 | Revisado: 18/08/2021 | Aceito: 25/08/2021 | Publicado: 27/08/2021

Beatriz Benny Sungaila Pereyra ORCID: https://orcid.org/0000-0003-1905-7923

Universidade Tiradentes, Brasil E-mail: biaspsa@gmail.com

Tatiane Batista dos Santos

ORCID: https://orcid.org/0000-0002-5807-4614

Universidade Tiradentes, Brasil

E-mail: Tatiane.bdos@souunit.com.br

Felipe Santos Rocha

ORCID: https://orcid.org/0000-0003-0749-3189

Universidade Tiradentes, Brasil

E-mail: felipe.srocha@ souunit.com.br

Bárbara de Jesus Costa

ORCID: https://orcid.org/0000-0002-3055-3429

Universidade Tiradentes, Brasil

E-mail: barbara_j.costa@hotmail.com

Any Gabrielly de Jesus Costa

ORCID: https://orcid.org/0000-0002-7788-679X Universidade Tiradentes, Brasil

E-mail: any.gabrielly@ souunit.com.br

Glenda Amaral da Silva

ORCID: https://orcid.org/0000-0002-2866-2052 Universidade Tiradentes, Brasil

E-mail: glendaamaral7@gmail.com

Francine Ferreira Padilha

ORCID: https://orcid.org/0000-0002-5892-4252 Universidade Tiradentes, Brasil

E-mail: francine_padilha@itp.org.br

Daniela Droppa-Almeida

ORCID: https://orcid.org/0000-0002-8154-1030

Universidade Tiradentes, Brasil

E-mail: danieladroppa@gmail.com

\section{Resumo}

A Tabebuia roseoalba, conhecida popularmente como Ipê-branco, uma planta nativa do cerrado e pantanal brasileiro. Por possuir inúmeras substâncias de interesse terapêutico, há perspectivas de servirem como alternativa no controle de infecções. Com o intuito de verificar a importância dos extratos de Tabebuia roseoalba no cunho científico, foram feitas pesquisas a fim de se confirmar a relevância que o presente trabalho apresenta como inovação tecnológica. Os resultados encontrados nas bases de dados Science Direct e Pubmed, assim como patentes encontradas nos bancos de patentes World Intelectual Property Organization (WIPO) e Instituto Nacional da Propriedade Industrial (INPI), foram métodos eficazes para a construção dessa Prospecção. A partir das palavras-chaves antimicrobianos, resistência bacteriana, Bignoniaceae, Tabebuia e Tabebuia roseoalba, na língua inglesa e portuguesa, quando necessário, na base de patentes WIPO revelou 135.638 patentes para antimicrobial, 78.108 para bacterial resistence, 69 para Bignoniaceae, 167 para Tabebuia e 0 para Tabebuia roseoalba. No INPI foram obtidas 1.377 para antimicrobiano, 2.510 para resistência bacteriana, 38 para Bignoniaceae, 31 para Tabebuia e 3 para Tabebuia roseoalba. A partir dos resultados obtidos mediante as buscas de patentes acerca da utilização de potenciais antimicrobiano de Tabebuia roseoalba para o combate de agentes patogênicos, pode-se concluir que o estudo forneceu dados de prospecção científico-tecnológico, visto que auxiliou como uma boa ferramenta para a realização da presente pesquisa pode-se ressaltar a importância da análise prospecção tecnológica, como um meio benéfico no qual pode promover a capacidade de organizar a pesquisa inovadora com base nos interesses e necessidades da sociedade.

Palavras-chave: Antimicrobianos; Resistência bacteriana; Tabebuia.

\begin{abstract}
Tabebuia roseoalba, popularly known as Ipê-branco, a plant native to the Brazilian cerrado and wetlands. As it has numerous substances of therapeutic interest, there are perspectives of serving as an alternative in the control of infections. In order to verify the importance of the extracts of Tabebuia roseoalba in the scientific nature, researches
\end{abstract}


were carried out in order to confirm the relevance that the present work presents as a technological innovation. The results found in the Science Direct and Pubmed databases, as well as the patents found in the World Intellectual Property Organization (WIPO) and National Institute of Industrial Property (INPI) patent databases, were effective methods for the construction of this Prospectus. From the keywords antimicrobial, bacterial resistance, Bignoniaceae, Tabebuia and Tabebuia roseoalba, in English and Portuguese, when necessary, the WIPO patent database revealed 135,638 patents for antimicrobial, 78,108 for bacterial resistance, 69 for Bignoniaceae, 167 for Tabebuia and 0 for Tabebuia roseoalba. The INPI obtained 1,377 for antimicrobial, 2,510 for bacterial resistance, 38 for Bignoniaceae, 31 for Tabebuia and 3 for Tabebuia roseoalba. From the results obtained through patent searches on the use of antimicrobial potentials from Tabebuia roseoalba to combat pathogens, it can be concluded that the study provided data from scientific-technological prospection, as it helped as a good tool for the carrying out this research, the importance of technological prospecting analysis can be highlighted, as a beneficial means in which it can promote the ability to organize innovative research based on the interests and needs of society.

Keywords: Antimicrobials; Bacterial resistance; Tabebuia.

\section{Resumen}

Tabebuia roseoalba, popularmente conocida como Ipê-branco, una planta nativa del cerrado brasileño y los humedales. Al contar con numerosas sustancias de interés terapéutico, existen perspectivas de servir como alternativa en el control de infecciones. Con el fin de verificar la importancia de los extractos de Tabebuia roseoalba en el carácter científico, se realizaron investigaciones con el fin de confirmar la relevancia que presenta el presente trabajo como innovación tecnológica. Los resultados encontrados en las bases de datos Science Direct y Pubmed, así como las patentes encontradas en las bases de datos de patentes de la Organización Mundial de la Propiedad Intelectual (OMPI) y el Instituto Nacional de Propiedad Industrial (INPI), fueron métodos efectivos para la construcción de este Prospecto. A partir de las palabras clave antimicrobiano, resistencia bacteriana, Bignoniaceae, Tabebuia y Tabebuia roseoalba, en inglés y portugués, cuando fue necesario, la base de datos de patentes de la OMPI reveló 135.638 patentes de antimicrobianos, 78.108 de resistencia bacteriana, 69 de Bignoniaceae, 167 de Tabebuia y 0 de Tabebuia roseoalba. El INPI obtuvo 1.377 por antimicrobiano, 2.510 por resistencia bacteriana, 38 por Bignoniaceae, 31 por Tabebuia y 3 por Tabebuia roseoalba. A partir de los resultados obtenidos a través de búsquedas de patentes sobre el uso de potenciales antimicrobianos de Tabebuia roseoalba para combatir patógenos, se puede concluir que el estudio aportó datos de prospección científico-tecnológica, ya que sirvió de buena herramienta para la realización de esta investigación, el Cabe destacar la importancia del análisis de la prospección tecnológica, como un medio beneficioso en el que se puede promover la capacidad de organizar investigaciones innovadoras en función de los intereses y necesidades de la sociedade.

Palabras clave: Antimicrobianos; Resistencia bacteriana; Tabebuia.

\section{Introdução}

A resistência bacteriana é a capacidade da bactéria em se multiplicar na presença de concentrações de fármacos que são inibidores desses microrganismos durante o uso terapêutico. Diante disso, o surgimento de bactérias resistentes é uma problemática de saúde que vem crescendo, principalmente devido ao uso incorreto de antibióticos. E em virtude disso, há uma demora no tratamento e aumento de custos trazendo prejuízos à saúde pública, pois à incompreensão do tratamento quanto à estrita necessidade em controlar as infecções associadas à saúde continuam sendo uma das maiores causas de morte na maioria dos países (Ayhan et al., 2016; Patini et al., 2020).

De acordo com Ayhan et al. (2016), a resistência bacteriana acontece através das mutações espontâneas ou transferência horizontal de genes. Nesse caso, existem vários mecanismos de resistência para que haja uma desativação ou eliminação desses antibióticos. Dentre estes mecanismos, destaca-se a produção de biofilmes. A habilidade das bactérias em formar biofilme é uma problemática que afeta dispositivos hospitalares ou tecidos lesionados é um fator de virulência para esse patógeno, especialmente em hospitais e centros de assistência à saúde onde a necessidade de utilização de antimicrobianos é alta e a formação de biofilme representa um problema grave devido a sobrevivência desses patógenos diante de fármacos (Neuberger, Du \& Luisi, 2018).

Em destaque, a bactéria Staphylococcus aureus é classificada como Gram-positivo e adquiriu resistência à meticilina, dando origem a $S$. aureus resistente à meticilina MRSA, sendo a segunda causa mais comum de Infecções Relacionadas à Assistência à Saúde (IRAS) nos EUA, de acordo com um relatório do Centers for Disease Control and Prevention (CDC) (Miller, Munita \& Arias, 2014; Malani, 2014; Horváth et al., 2016; Gomes et al., 2018; Pugazhendhi et al., 2020). No entanto, 
as estratégias para lidar com essa problemática vão desde a necessidade uma maior compreensão desses patógenos a buscas de novas formas de controle e eliminação dessa infecção no hospedeiro. Além disso, há também uma necessidade crescente em traçar novas estratégias para interromper ou retardar a evolução dessa resistência aos antibióticos na saúde mundial (Cogen et al., 2020).

Nesse contexto, o uso dos fitoterápicos tem sido um grande aliado para reverter essa problemática, pois tem sido utilizado, muitas vezes, como uma alternativa no tratamento seguro, de baixo custo, eficaz e de qualidade frente a infecções bacterianas (Feitosa et al., 2016). Além do mais, os extratos de plantas medicinais apresentam diversas atividades farmacológicas, tais como: potencial antibacteriano, antifúngico, antitumoral, antidiabético, anti-inflamatório, dentre outros (Ferraz-filha et al., 2017; Prasathkumar et al., 2021). Diante disso, com essas diversas atividade potenciais o isolamento desses compostos bioativos eficazes e com toxicidade seletiva contra bactérias, a exemplo o $S$. aureus é recorrente e tem servido como uma alternativa real para os próximos anos (Alvarenga et al., 2016; Hemeg et al., 2020).

De acordo com estudos de Hamed et al. (2020) e El-Hawary et al. (2021) família Bignoniaceae possui gêneros que as plantas apresentam diversas atividades farmacológicas já relatas na literatura, destaca-se nesse contexto a Tabebuia roseoalba. Essa espécie é conhecida popularmente como Ipê-branco e é nativa do cerrado e pantanal brasileiro. Visto que a literatura científica disponível evidencia que as plantas da família Bignoniaceae proporcionam excelente potencial para novos estudos científicos, com procedência na descoberta de novas substâncias de interesse terapêutico, torna-se indispensável o estudo dos extratos da espécie Tabebuia roseoalba com a perspectiva no controle da infecção. Assim como as buscas tecnológicas tentando compreender o cenário das patentes utilizando plantas e especificamente essa família, gênero e espécie (Romano, 2014; Ferreira-júnior et al., 2015; Ferraz-filha et al., 2016; Chaves filho \& Borges, 2018; Mazzei et al., 2020).

Vale ressaltar a importância que as análises prospectivas, cientificas e tecnológicas trazem para a pesquisa. Através desse tipo de estudo é possível compreender o cenário de um país pela possibilidade em empregar a propriedade intelectual como solução dos problemas sociais. Assim como compreender se as pesquisas de maneira geral estão sendo convertidas de fato para solução desses problemas, podendo contribuir para a redução de óbitos e gastos dos serviços de saúde. Diante desse contexto, o objetivo desse artigo foi realizar uma prospecção científica e tecnológica em busca de artigos e patentes com o uso de extrato natural como potencial antimicrobiano, tendo como ponto principal o uso da Tabebuia roseoalba (Hamed et al., 2020; El-hawary et al., 2021).

\section{Metodologia}

Esse estudo trata-se de uma pesquisa de caráter exploratório e quali-quantitativa, cujo levantamento dos dados para a prospecção científica e tecnológica aconteceu de 05 de janeiro de 2021 a 20 de fevereiro de 2021. Em relação a prospecção científica foi adotada uma metodologia de revisão de literatura sistemática que auxiliam nortear o mapeamento do tema a ser tratado de maneira mais assertiva, possibilitando um melhor direcionamento na investigação (Chueke \& Amatucci, 2015). Nesse contexto, utilizou-se uma estratégia capaz de recuperar todas as publicações relevantes nas bases de dados utilizadas. Essas etapas precisam ser criteriosamente seguidas no intuito de fornecer uma análise real acerca a produção cientifica, no entanto, sabe-se que interferentes como temas multidisciplinares podem comprometer a análise (Lima \& Velho Faria, 2007; Menezes; vieira \& Dos santos, 2020; De Oliveira Lima et al., 2020).

As buscas foram conduzidas com as seguintes palavras-chaves: "Antimicrobial”, "Bacterial Resistence”, "Bignoniaceae ", "Tabebuia" e "Tabebuia roseoalba" utilizadas isoladas e combinadas entre si por meio do operador booleano AND, nos seguintes bancos de dados Science Direct e Pubmed, analisando os últimos dez anos (2012 a 2021). Para as buscas de patentes, foram utilizados os mesmos critérios, já mencionados anteriormente, referentes às palavras-chaves, operador booleano e anos de publicação no banco de dados do Google Patentes e nesta plataforma para as buscas de patentes brasileiras 
os filtros em relação ao escritório de patentes foram selecionados, o primeiro com a opção "BR" enquanto o segundo em relação a linguagem foi selecionado "português".

Para as buscas internacionais o escritório de patentes foi selecionado a opção "WO" referente ao WIPO (Organização Mundial da Propriedade Intelectual) e a linguagem selecionada foi "inglês". As prospecções tecnológicas podem fornecer informações potencialmente estratégicas, como: embasamento no processo de gestão, acompanhamento tecnológico e de avaliação de empresas e até mesmo de países em comparação à concorrência (Amparo, Ribeiro \& Guarieiro, 2012).

A estratégia de pesquisa visou garantir que a maior parte das patentes com as palavras-chaves fosse localizada e processada. Para determinação do código utilizado para as pesquisas, utilizou a Classificação Cooperativa de Patentes (CPC) que é de acesso livre usualmente selecionada para prospecções tecnológicas. As CPCs que mais estiveram de acordo com a temática foram a A61K (PREPARAÇÕES PARA FINALIDADES MÉDICAS, ODONTOLÓGICAS OU HIGIÊNICAS) e A61P (ATIVIDADE TERAPÊUTICA ESPECÍFICA DE COMPOSTOS QUÍMICOS OU PREPARAÇÕES MEDICINAIS). Dessa forma, foi realizado um estudo comparativo entre a base de dados de artigos científicos e os depósitos de patentes relacionadas às tecnologias utilizadas para ação antimicrobiana.

\section{Resultados e Discussão}

Diante das buscas de artigos científicos e patentes com a associação das palavras-chaves "Antimicrobial and Tabebuia" foi possível selecionar os documentos necessários para o estudo tecnológico, os resultados estão descritos na Tabela 1.

Tabela 1. Palavras-chaves e seus respectivos resultados nas bases de dados analisadas realizadas em janeiro de 2021.

\begin{tabular}{l|llll}
\hline \multicolumn{5}{l}{ BASES DE DADOS } \\
\hline PALAVRAS-CHAVES & Science Direct & Pubmed & Brasil & WIPO \\
Antimicrobial & 184.633 & 520.207 & 1.377 & 135.638 \\
Bacterial resistence & 29.468 & 116.326 & 2.510 & 78.108 \\
Bignoniaceae & 2.677 & 278 & 38 & 69 \\
Tabebuia & 1.350 & 147 & 31 & 167 \\
Tabebuia roseoalba & 14 & 6 & 3 & 0 \\
Antimicrobial and Bignoniaceae & 505 & 198 & 7 & 41 \\
Antimicrobial and Tabebuia & 201 & 78 & 4 & 78 \\
Antimicrobial and Tabebuia roseoalba & 0 & 3 & 2 & 0 \\
Bacterial resistence and Bignoniaceae & 28 & 8 & 7 & 26 \\
Bacterial resistence and Tabebuia & 24 & 2 & 4 & 46 \\
Bacterial resistence and Tabebuia roseoalba & 0 & 0 & 1 & 0 \\
\hline
\end{tabular}

Fonte: Elaborada pelos autores deste artigo, a partir das bases de dados Science Direct, Pubmed, INPI e Wipo realizadas em 2021. 
Quando analisados os resultados encontrados com as palavras-chaves citadas anteriormente na análise de artigos, foi possível observar que há um número maior relacionado com "antimicrobial” no Pubmed ao se comparar com o Science Direct, 520.207 e 184.633, respectivamente. O mesmo foi observado em relação a palavra-chave "Bacterial resistence" onde foram encontrados 116.326 artigos no Pubmed e 29.468 no Science Direct. No entanto, ao utilizar a palavra-chave "Bignoniaceae" observou-se um quantitativo maior de artigos no Science Direct (2.677) em relação ao Pubmed (278) e a isso se deve ao foco que cada banco de dados oferece. O Pubmed possui artigos voltados para a medicina, compreendendo mais a área da saúde como um todo. Já o Science Direct apresenta um escopo muito maior, apresentando uma maior variedade nos temas. Ao se analisar os artigos com a palavra-chave "Bignoniaceae" no Science Direct, as áreas que mais estão relacionadas com o nosso tema foram "Farmacologia, toxicologia e ciências farmacêuticas", "Medicina e Odontologia" e "Imunologia e Microbiologia", totalizando 875 artigos, as demais áreas encontradas estão descritas na Figura 1.

Figura 1. Gráfico ilustrativo relatando a diversidade de áreas dos artigos encontrados com a palavra-chave "Bignoniaceae" na base de dados do Science Direct.

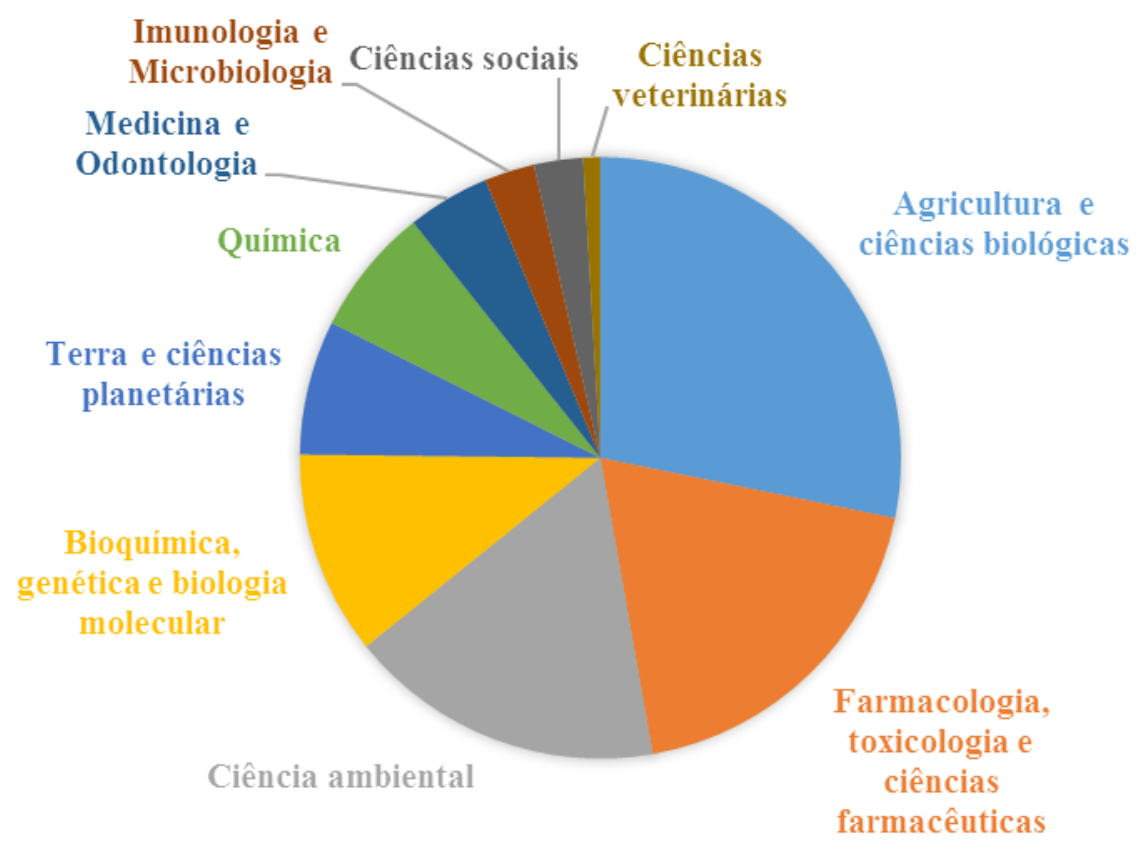

Fonte: Elaborada pelos autores deste artigo, a partir das bases de dados Science Direct realizadas em 2021.

Em relação as palavras-chaves "Tabebuia" e "Tabebuia roseoalba" o mesmo pode ser observado em relação ao quantitativo obtido no Pubmed (147) e no Science Direct (737) para "Tabebuia" e, para "Tabebuia roseoalba" um total de 6 e 14 para o Pubmed e Science Direct, respectivamente. Porém, ao correlacionar com as áreas que estão mais de acordo com as análises, as mesmas utilizadas na palavra-chave "Bignoniaceae", um total de 363 artigos com a palavra-chave "Tabebuia" e 3 com a palavra-chave "Tabebuia roseoalba" foram observados. As demais áreas para ambas palavras-chaves estão descritas na Figura 2. 
Figura 2. Gráficos ilustrativos relatando a diversidade de áreas dos artigos encontrados com as palavras-chaves "Tabebuia" e "Tabebuia roseoalba" na base de dados do Science Direct. A) Resultados com a utilização da palavra-chave "Tabebuia" e suas respectivas áreas de acordo com o Science Direct; B) Resultados com a utilização da palavra-chave "Tabebuia roseoalba" e suas respectivas áreas de acordo com o Science Direct.

A)

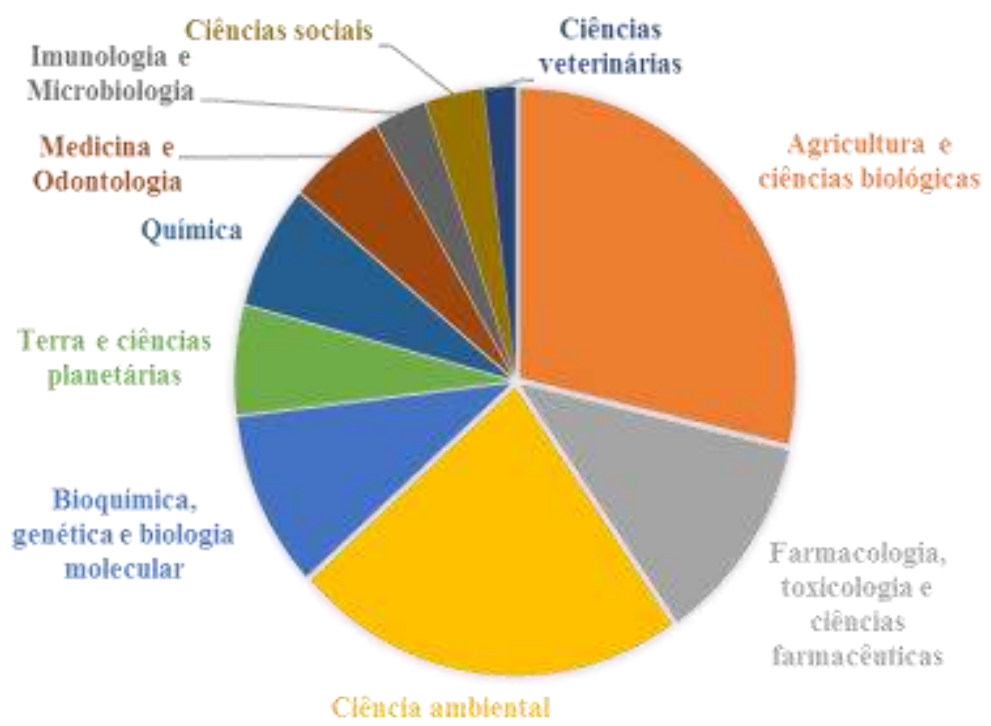

B)

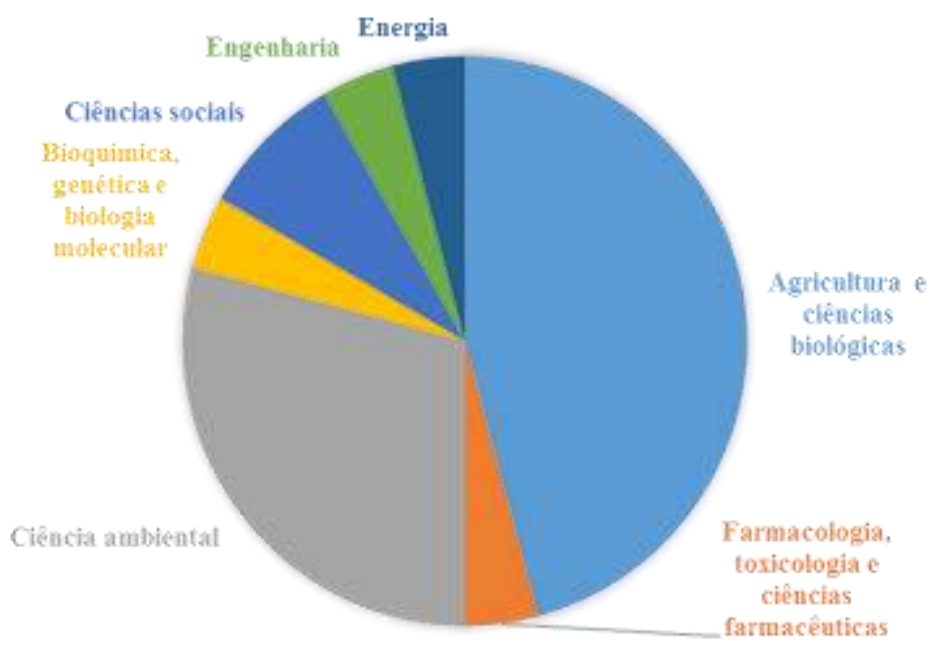

Fonte: Elaborada pelos autores deste artigo, a partir das bases de dados Science Direct realizadas em 2021.

De acordo com os resultados encontrados com auxílio do operador booleano AND entre as palavras-chaves "Antimicrobial AND Bignoniaceae" e "Antimicrobial AND Tabebuia” foi observado um quantitativo de artigos maior no Science Direct ao se comparar com o Pubmed, sendo necessário também verificar as áreas para que os artigos relacionados com os temas fossem devidamente selecionados. Ao se relacionar com as mesmas áreas descritas para a palavra-chave "Bignoniaceae" o quantitativo de artigos passou de 505 para 320 a partir da associação "Antimicrobial AND Bignoniaceae" enquanto, "Antimicrobial AND Tabebuia" passou de 201 para 114. As demais áreas encontradas para ambas associações descritas acima se encontra na Figura 3. 
Figura 3. Áreas encontradas e seus respectivos quantitativos de artigos com as associações "Antimicrobial AND Bignoniaceae" e "Antimicrobial AND Tabebuia" no Science Direct.

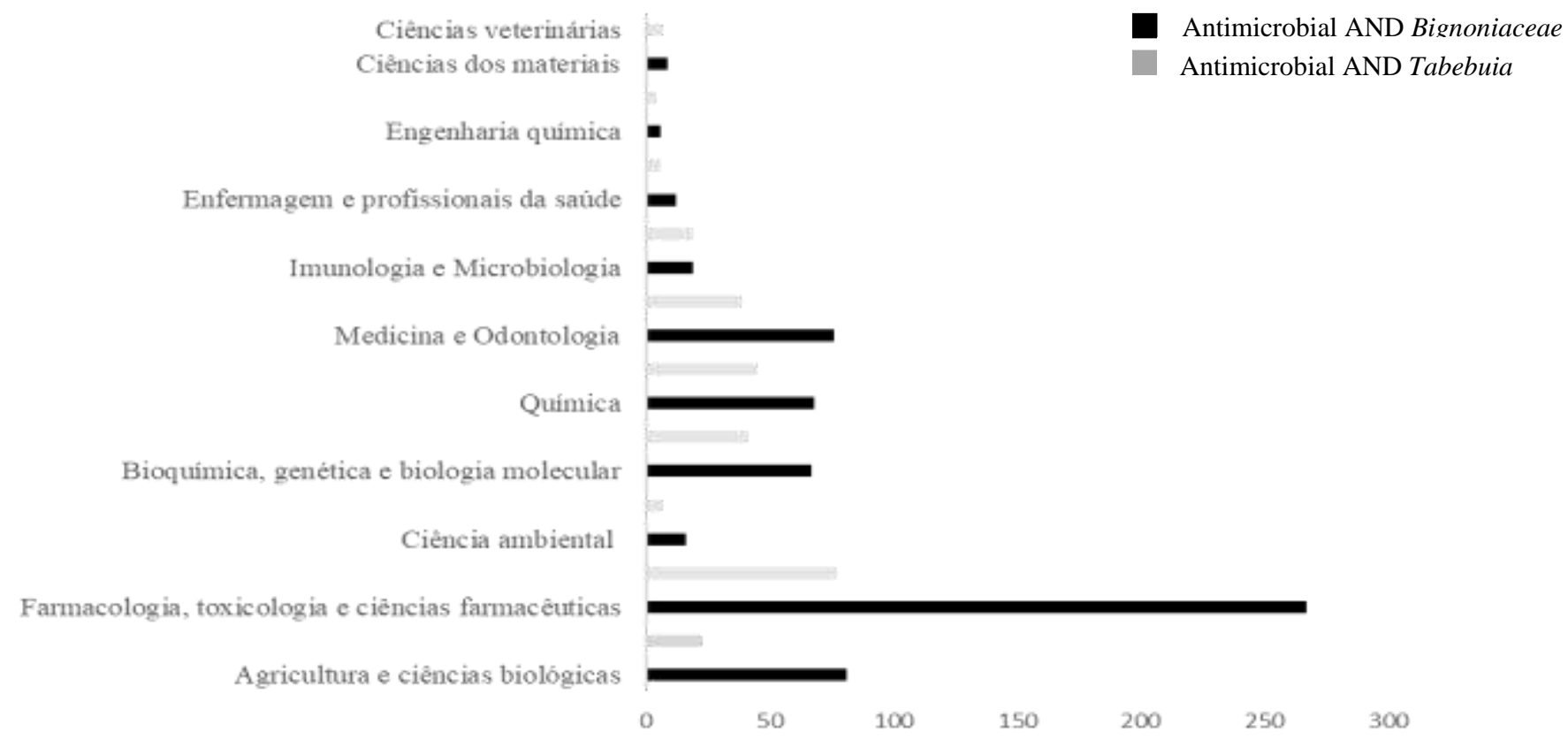

Fonte: Elaborada pelos autores deste artigo, a partir das bases de dados Science Direct realizadas em 2021.

Ao relacionar as palavras-chaves "Bacterial resistence and Bignoniaceae" e "Bacterial resistence and Tabebuia" observou-se o mesmo padrão, o quantitativo de artigos no Science direct foi superior ao do Pubmed, como descrito na tabela 1. Ao analisar as áreas dos artigos com essas associações selecionando as mesmas áreas já descritas anteriormente, um total de 5 artigos foram selecionados para a associação "Bacterial resistence AND Bignoniaceae" e 8 com a associação "Bacterial resistence AND Tabebuia". As demais áreas encontradas para ambas associações estão na Figura 4. 
Figura 4. Áreas encontradas e seus respectivos quantitativos de artigos com as associações "Bacterial resistence AND Bignoniaceae" e "Bacterial resistence AND Tabebuia" no Science Direct.

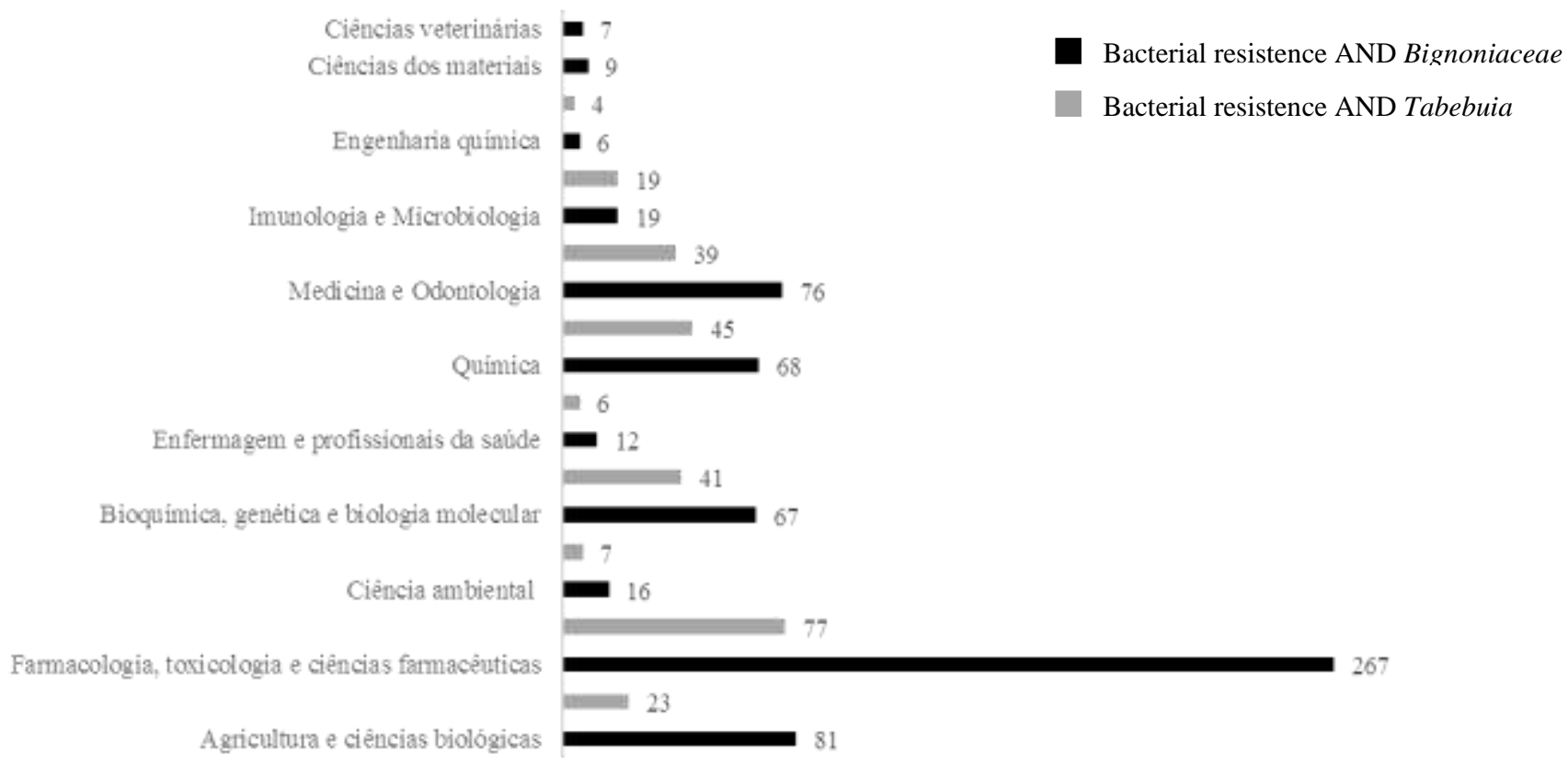

Fonte: Elaborada pelos autores deste artigo, a partir das bases de dados Science Direct realizadas em 2021.

Diante da prospecção científica a associação que mais teve relação com o tema de estudo foi "Antimicrobial AND Tabebuia" como dito anteriormente, dos 78 artigos, apenas dois os quais relatam o uso da T. roseoalba e sua atividade antiinflamatória e antinociceptiva. Os demais artigos falam sobre outras espécies de Tabebuia e ressaltam a diversidade de atividades farmacológicas que esse gênero possui (Figura 5). Um total de 14 atividades potenciais diferentes já foram descritas na literatura sobre esse gênero e a maioria dos artigos atribui esses potenciais a três principais compostos: Lapachol, $\beta$ Lapachona e $\alpha$-Lapachona. Esses compostos são derivados das naftoquinonas que são metabólitos secundários das plantas e dividem-se em 1,2- e 1,4-naftoquinonas e, em função da presença de anel heterocíclico oxigenado, ainda podem ser classificadas como prenilnaftoquinonas, furanonaftoquinonas, difuronaftoquinonas e piranonaftoquinonas, apresentando diversidade em relação a sua estrutura dentro do gênero Tabebuia (Linzner et al., 2020). 
Figura 5. Ilustração acerca das espécies de Tabebuias encontradas nos 78 artigos com o uso das associações "Antimicrobial AND Tabebuia" no Pubmed, seguido de todas as atividades farmacológicas já descritas na literatura.

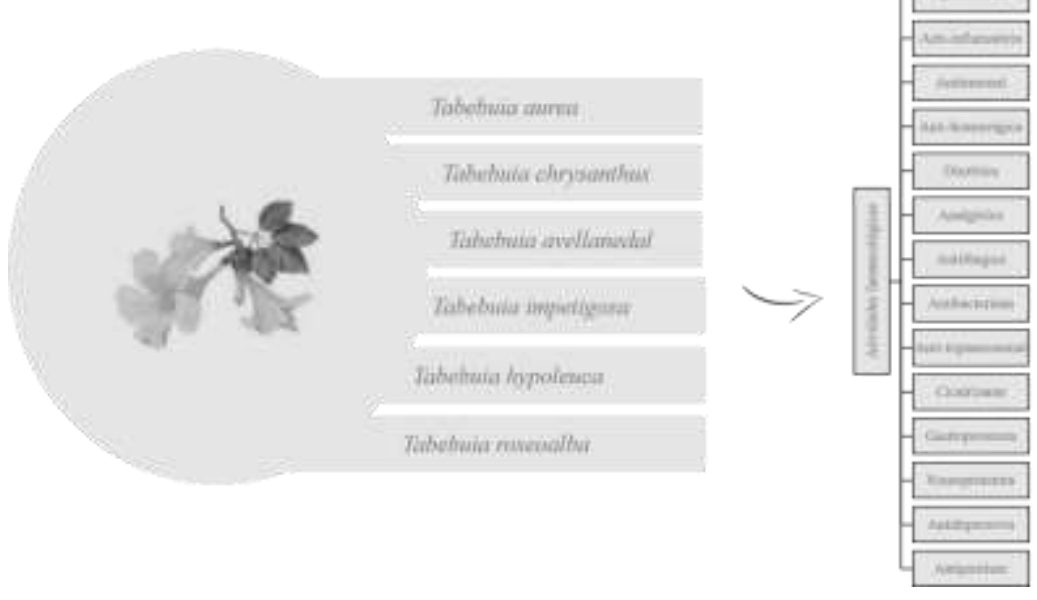

Fonte: Elaborada pelos autores deste artigo, a partir das bases de dados Science Direct e Pubmed realizadas em 2021.

Já em relação as buscas de patentes nos últimos 10 anos (2012 a 2021) observou-se um total de 1.377 patentes depositadas no Brasil com a palavra-chave "Antimicrobiano", 2.510 patentes utilizando "Resistência bacteriana", 38 com "Bignoniaceae", 31 com "Tabebuia" e 3 com "Tabebuia roseoalba", dados descritos na Figura 6. Ao cruzar os dados encontrados com os CPCs previamente relatados na metodologia, pode-se observar, "Antimicrobiano" + A61K obteve um total de 517 resultados. Quando o cruzamento aconteceu com "Antimicrobiano" + A61P um total de 281 patentes foram correlacionadas. Os cruzamentos com "Resistência bacteriana" + A61K ou A61P, trouxeram de resultados, respectivamente, 866 e 725 patentes; já os resultados correlacionando "Bignoniaceae" + A61K ou A61P foi de 5 e 4, respectivamente; para "Tabebuia" e "Tabebuia roseoalba" + A61K ou A61P foi de 1 e 0, respectivamente.

Ainda em relação as patentes depositadas exclusivamente no Brasil utilizando as palavras-chaves associadas “Antimicrobiano AND Bignoniacea", "Antimicrobiano AND Tabebuia" e "Antimicrobiano AND Tabebuia roseoalba" quando cruzadas com os CPCs A61K ou A61P apresentou apenas uma patente para A61K em todas as correlações com as associações mencionadas. Já em relação as associações "Resistência bacteriana AND Tabebuia" e "Resistência bacteriana AND Tabebuia roseoalba" quando cruzadas apresentou apenas uma patente para A61K, enquanto "Resistência bacteriana AND Bignoniaceae" apresentou apenas uma patente para A61P.

Esses cruzamentos permitem filtrar de maneira mais assertiva as patentes em relação ao tema proposto, visto que muitas patentes contendo extratos ou mesmo atividade antimicrobiana são também voltadas para desenvolvimento de cerâmicas, tecidos, biopesticidas, dentre outros. Ou seja, de um total de 1.377 patentes encontradas quando correlacionadas com o CPC A61K que possui invenções voltadas para "PREPARAÇÕES PARA FINALIDADES MÉDICAS, ODONTOLÓGICAS OU HIGIÊNICAS” acabou filtrando apenas 517 patentes, enquanto que com o CPC A61P que se trata de invenções voltadas para “ATIVIDADE TERAPÊUTICA ESPECÍFICA DE COMPOSTOS QUÍMICOS OU PREPARAÇÕES MEDICINAIS" filtrou 281 patentes.

Ao analisar os demais CPCs encontrados relacionados com essa palavra-chave em questão, encontramos: A61Q “USO ESPECÍFICO DE COSMÉTICOS OU PREPARAÇÕES SIMILARES PARA HIGIENE PESSOAL”, A01N “CONSERVAÇÃO DE CORPOS DE SERES HUMANOS OU ANIMAIS OU PLANTAS OU PARTES DOS MESMOS (preservação de alimentos ou produtos alimentícios A23); BIOCIDAS, p. ex. COMO DESINFETANTES, COMO PESTICIDAS OU COMO HERBICIDAS (preparações para fins medicinais, dentários ou toalete que matam ou previnem o crescimento ou proliferação de organismos indesejados A61K); REPELENTES OU ATRATIVOS DE PESTES; 
REGULADORES DO CRESCIMENTO DE PLANTAS" e A61L "MÉTODOS OU APARELHOS PARA ESTERILIZAR MATERIAIS OU OBJETOS EM GERAL; DESINFECÇÃO, ESTERILIZAÇÃO OU DESODORIZAÇÃO DO AR; ASPECTOS QUÍMICOS DE ATADURAS, CURATIVOS, ALMOFADAS ABSORVENTES OU ARTIGOS CIRÚRGICOS; MATERIAIS PARA ATADURAS, CURATIVOS, ALMOFADAS ABSORVENTES OU ARTIGOS CIRÚRGICOS" os quais não possuem relação com o tema proposto. As demais palavras-chaves e seus outros CPCs encontrados encontra-se na tabela 2.

Figura 6. Gráfico referente ao total de patentes encontradas com as respectivas palavras-chaves depositadas no Brasil, seguindo com as correlações realizadas com os CPCs previamente selecionados por possuírem relação com o tema proposto (A61K e A61P). Essas correlações servem como um filtro, visto que há diversas utilizações de extratos e seu potencial antimicrobiano.

10000

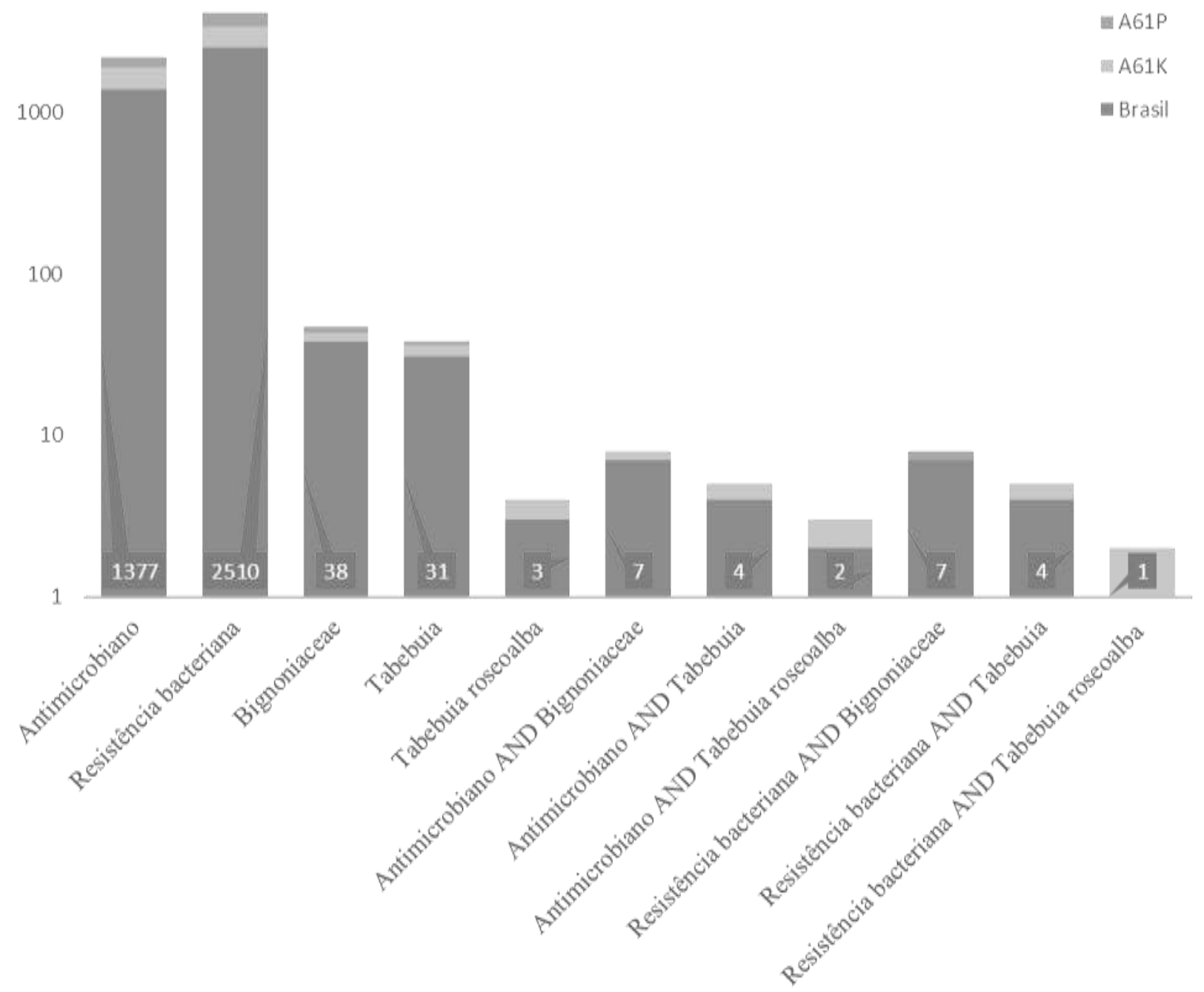

Fonte: Elaborada pelos autores deste artigo, a partir das bases de dados Google patentes realizadas em 2021. 
Tabela 2. Resultados das palavras-chaves e seus respectivos CPCs relacionados e seus principais depositantes.

\begin{tabular}{|c|c|c|c|c|}
\hline & Brasil $(C P C)^{*}$ & Depositantes** & Wipo $(C P C)^{*}$ & Depositantes** \\
\hline Antimicrobial & $\begin{array}{ll}\text { A61Q, } & \text { A01N, } \\
\text { A61L, } & \text { C12N e } \\
\text { C07K } & \end{array}$ & $\begin{array}{l}\text { Colgate-Palmolive } \\
\text { Company, Unilever, The } \\
\text { Procter \& Gamble } \\
\text { Company, Kimberly- } \\
\text { Clark Worldwide, Inc., } \\
\text { Symrise Ag; }\end{array}$ & $\begin{array}{l}\text { A01N, A61L, Y02A, } \\
\text { A61Q e C07K }\end{array}$ & $\begin{array}{l}\text { Becton, Dickinson And } \\
\text { Company, Unilever N.V., } \\
\text { Conopco, Inc., D/B/A } \\
\text { Unilever, Unilever Plc, } \\
\text { Ecolab Usa Inc. }\end{array}$ \\
\hline Bacterial resistence & $\begin{array}{l}\mathrm{C} 12 \mathrm{n} \\
\mathrm{A} 01 \mathrm{~N}, \quad \mathrm{Y} 02 \mathrm{~A}, \\
\mathrm{C} 12 \mathrm{Y}\end{array}$ & $\begin{array}{l}\text { Dow Agrosciences Llc, } \\
\text { Basf Se, KWS SAAT SE } \\
\& \text { Co. KGaA, } \\
\text { Novozymes A/S, } \\
\text { Universidade Estadual } \\
\text { De Campinas - Unicamp }\end{array}$ & $\begin{array}{l}\text { CN12, Y02A, C07K, } \\
\text { C12Q e C07D }\end{array}$ & $\begin{array}{l}\text { Wockhardt Limited, The } \\
\text { Regents Of The University } \\
\text { Of California, Helperby } \\
\text { Therapeutics Limited, } \\
\text { President And Fellows Of } \\
\text { Harvard College, } \\
\text { Massachusetts Institute Of } \\
\text { Technology }\end{array}$ \\
\hline Bignoniaceae & $\begin{array}{l}\mathrm{A} 01 \mathrm{~N}, \quad \mathrm{C} 12 \mathrm{~N}, \\
\text { A61L, } \\
\text { Y02P }\end{array}$ & $\begin{array}{l}\text { Universidade Federal Do } \\
\text { Maranhão, Sandra } \\
\text { Aparecida De Assis, } \\
\text { Farmhannong Co., Ltd., } \\
\text { Universidade Federal Do } \\
\text { Paraná, Sabic Global } \\
\text { Technologies B.V. }\end{array}$ & $\begin{array}{l}\mathrm{C} 12 \mathrm{~N}, \mathrm{~A} 01 \mathrm{~N}, \mathrm{C} 05 \mathrm{C} \\
\mathrm{C} 07 \mathrm{~K} \text { e } \mathrm{C} 12 \mathrm{Y}\end{array}$ & $\begin{array}{l}\text { Sabic Global Technologies } \\
\text { B.V., Carnegie Institution Of } \\
\text { Washington, Farmhannong } \\
\text { Co., Ltd., Boston } \\
\text { Biomedical, Inc., Syngenta } \\
\text { Participations Ag }\end{array}$ \\
\hline Tabebuia & $\begin{array}{l}\text { C12P, A61Q, } \\
\text { A01N, A01G e } \\
\text { Y02A }\end{array}$ & $\begin{array}{l}\text { Universidade Federal Do } \\
\text { Paraná, Universidade } \\
\text { Federal De Minas Gerais, } \\
\text { Marco Aurélio Donatoni, } \\
\text { Inst De Tecnologia E } \\
\text { Pesquisa, Buckman } \\
\text { Laboratories } \\
\text { International, Inc }\end{array}$ & $\begin{array}{l}\text { A01N, A23L, A61L, } \\
\text { A61Q e Y02P }\end{array}$ & $\begin{array}{l}\text { The Procter \& Gamble } \\
\text { Company, Buzzelet } \\
\text { Development And } \\
\text { Technologies Ltd., Shell } \\
\text { Internationale Research } \\
\text { Maatschappij B.V., Shell Oil } \\
\text { Company, Gas Technology } \\
\text { Institute }\end{array}$ \\
\hline Tabebuia roseoalba & $\begin{array}{l}\text { A01C, A01G, } \\
\text { A01N e A61Q }\end{array}$ & $\begin{array}{l}\text { Instituto De Tecnologia } \\
\text { E Pesquisa, Universidade } \\
\text { Tiradentes, Interludium } \\
\text { Mineraçao Ltda Epp }\end{array}$ & $\mathrm{X}$ & $\mathrm{X}$ \\
\hline
\end{tabular}




\begin{tabular}{|c|c|c|c|c|}
\hline $\begin{array}{l}\text { Antimicrobial } \\
\text { Bignoniaceae }\end{array}$ & $\begin{array}{l}\text { A01N, A61L, } \\
\text { C120, A61F e } \\
\text { B32B }\end{array}$ & $\begin{array}{l}\text { Sandra Aparecida De } \\
\text { Assis, Universidade } \\
\text { Federal De Alagoas - } \\
\text { Ufal, Univ Fed Rural De } \\
\text { Pernambuco, Secretaria } \\
\text { Executiva De Saúde } \\
\text { Pública Do Estado Do } \\
\text { Pará, Univ Minas Gerais }\end{array}$ & $\begin{array}{l}\mathrm{C} 12 \mathrm{~N}, \mathrm{C} 07 \mathrm{~K}, \mathrm{~A} 01 \mathrm{~N} \\
\mathrm{C} 12 \mathrm{Y} \text { e } \mathrm{A} 01 \mathrm{H}\end{array}$ & $\begin{array}{l}\text { Carnegie Institution Of } \\
\text { Washington,,Farmhannong } \\
\text { Co., Ltd.,,Spogen Biotech } \\
\text { Inc.,,Bio-Bee Sde Eliyahu } \\
\text { Ltd.,,Boston Biomedical, Inc. }\end{array}$ \\
\hline Antimicrobial and Tabebuia & $\begin{array}{l}\text { A61Q, } \mathrm{A} 23 \mathrm{~L}, \\
\text { C12R, A23P e } \\
\text { B01D }\end{array}$ & $\begin{array}{l}\text { Maria Das Graças } \\
\text { Carneiro Da Cunha, } \\
\text { Universidade Tiradentes, } \\
\text { Fundação Universidade } \\
\text { De Caxias Do Sul, Basf } \\
\text { Beauty Care Solutions } \\
\text { France Sas }\end{array}$ & $\begin{array}{l}\text { A01N, A23L, A61Q, } \\
\text { C07D e A61L }\end{array}$ & $\begin{array}{l}\text { The Procter \& Gamble } \\
\text { Company, Athenion Ag, Basf } \\
\text { Beauty Care Solutions France } \\
\text { Sas, 孙广娥, The Board Of } \\
\text { Regents Of The University } \\
\text { Of Texas System }\end{array}$ \\
\hline $\begin{array}{l}\text { Antimicrobial and Tabebuia } \\
\text { roseoalba }\end{array}$ & A01N e A61Q & $\begin{array}{l}\text { Instituto de tecnologia e } \\
\text { Pesquisa, Universidade } \\
\text { Tiradentes, }\end{array}$ & $\mathrm{X}$ & $\mathrm{X}$ \\
\hline $\begin{array}{l}\text { Bacterial resistence and } \\
\text { Bignoniaceae }\end{array}$ & $\begin{array}{l}\mathrm{C} 12 \mathrm{~N}, \quad \mathrm{~A} 61 \mathrm{Q}, \\
\mathrm{A} 01 \mathrm{~N}, \\
\mathrm{C} 12 \mathrm{Y}\end{array}$ & $\begin{array}{l}\text { Sandra Aparecida De } \\
\text { Assis, Caris Life } \\
\text { Sciences Switzerland } \\
\text { Holdings Gmbh, Inst De } \\
\text { Tecnologia E Pesquisa, } \\
\text { Univ Tiradentes, Toyama } \\
\text { Prefectural University }\end{array}$ & $\begin{array}{l}\mathrm{C} 12 \mathrm{~N}, \mathrm{~A} 01 \mathrm{~N}, \mathrm{C} 07 \mathrm{~K} \\
\text { Y02A e A01H }\end{array}$ & $\begin{array}{l}\text { Carnegie Institution Of } \\
\text { Washington, Sabic Global } \\
\text { Technologies B.V., Spogen } \\
\text { Biotech Inc., Syngenta } \\
\text { Participations Ag, Dongbu } \\
\text { Farm Hannong Co., Ltd. }\end{array}$ \\
\hline $\begin{array}{l}\text { Bacterial resistence and } \\
\text { Tabebuia }\end{array}$ & $\begin{array}{l}\mathrm{A} 23 \mathrm{~V}, \quad \mathrm{C} 12 \mathrm{~N}, \\
\mathrm{C} 12 \mathrm{P}, \quad \mathrm{A} 23 \mathrm{~K} \text { e } \\
\mathrm{A} 01 \mathrm{~N}\end{array}$ & $\begin{array}{l}\text { Eulália Camelo Pessoa } \\
\text { De Azevedo Ximenes, } \\
\text { Commissariat A } \\
\text { L'energie Atomique Et } \\
\text { Aux Energies } \\
\text { Alternatives, Hipofi, Inst } \\
\text { De Tecnologia E } \\
\text { Pesquisa, Univ } \\
\text { Tiradentes }\end{array}$ & $\begin{array}{l}\text { A01N, A23L, C07D, } \\
\text { C09D e A23V }\end{array}$ & $\begin{array}{l}\text { Constance Therapeutics, Inc., } \\
\text { Bayer Cropscience Ag, The } \\
\text { Board Of Regents Of The } \\
\text { University Of Texas System, } \\
\text { Akeso Biomedical, Inc., } \\
\text { Nbvd S.A. }\end{array}$ \\
\hline $\begin{array}{l}\text { Bacterial resistence and } \\
\text { Tabebuia roseoalba }\end{array}$ & A61Q e A01N & $\begin{array}{l}\text { Instituto de tecnologia e } \\
\text { Pesquisa, Universidade } \\
\text { Tiradentes, }\end{array}$ & $\mathrm{X}$ & $\mathrm{X}$ \\
\hline
\end{tabular}

*Referente aos 5 principais CPCs encontrados, sem contar com os A61K e A61P.

** Referente aos 5 principais depositantes.

Fonte: Elaborada pelos autores deste artigo, a partir das bases de dados Google Patentes realizadas em 2021. 
Após as análises das patentes depositadas no Brasil, pesquisas para obtenção de um parâmetro mundial, foram realizadas selecionando o WIPO como banco de dados (Figura 7). Nesse contexto, observou-se um total de 135.638 com a palavra-chave "Antimicrobial", 78.108 patentes com a "Bacterial resistence", 69 com "Bignoniaceae", 167 com "Tabebuia" e nenhuma com "Tabebuia roseoalba". As mesmas correlações com as palavras-chaves e os CPCs A61K e A61P foram realizadas, obtendo um total de 69.943 e 51.388 patentes para "Antimicrobial" + A61K ou A61P, 32.211 e 24,696 para "Bacterial resistence" + A61K ou A61P, 23 e 17 para "Bignoniaceae" + A61K ou A61P e, por fim, 61 e 36 patentes para "Tabebuia" + A61K ou A61P, respetivamente, para todos os dados citados. Em relação a "Tabebuia roseoalba" nenhum dado foi encontrado.

Os resultados acerca das associações entre as palavras-chaves também foram cruzados com os CPCs, apresentando resultados somente quando os cruzamentos foram entre "Antimicrobial AND Bignoniaceae", "Antimicrobial AND Tabebuia", "Bacterial resistence AND Bignoniaceae" e "Bacterial resistence AND Tabebuia" todos cruzados com A61K e A61P, dando um total, respectivamente, de 20 e 14 para "Antimicrobial AND Bignoniaceae", 44 e 27 para "Antimicrobial AND Tabebuia", 6 e 5 "Bacterial resistence AND Bignoniaceae" e 23 e 16 para "Bacterial resistence AND Tabebuia". As demais informações acerca dos CPCs encontrados com essas palavras-chaves no WIPO estão descritas na tabela 2. 
Figura 7. Gráfico referente ao total de patentes encontradas com as respectivas palavras-chaves depositadas no Wipo, seguindo com as correlações realizadas com os CPCs previamente selecionados por possuírem relação com o tema proposto (A61K e A61P). Essas correlações servem como um filtro, visto que há diversas utilizações de extratos e sua potencial atividade antimicrobiana.

\section{0}

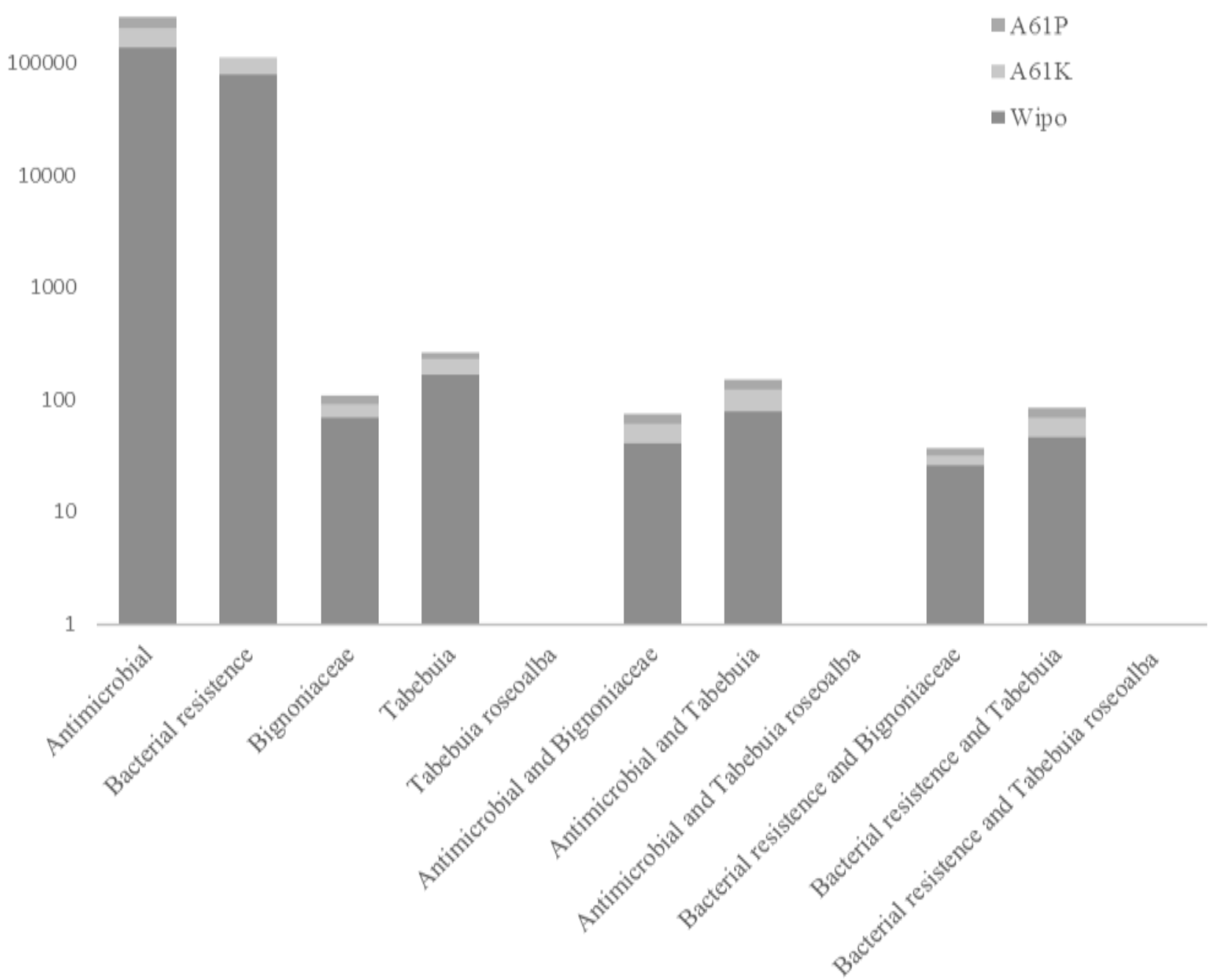

Fonte: Elaborada pelos autores deste artigo, a partir das bases de dados Google Patentes realizadas em 2021.

Após as análises pode-se observar a carência sobre o tema, utilizando a Tabebuia roseoalba, principalmente com as buscas realizadas no WIPO, pois entre as buscas realizadas nos depósitos brasileiros, pode-se encontrar com a palavra-chave "Tabebuia roseoalba" apresentou 3 patentes depositadas em território nacional. A isso se deve a presença desse gênero entre diversas regiões do país e devido a algumas espécies serem endêmicas do Brasil. A Tabebuia roseoalba é nativa do cerrado e pantanal brasileiro e, por conta disso, tanto os artigos encontrados com essa espécie e as 3 patentes foram produções brasileiras.

Essa planta apresenta algumas propriedades farmacológicas importantes já evidenciadas, como: potencial antinociceptivo com o uso de sua casca e (Ferreira-junior et al., 2014) atividade antimicrobiana por extrações feitas com a casca, folhas e caule (Gai, Dos santos \& Vieira, 2017), ainda possui atividades citotóxicas e antimicrobianas a partir dos microrganismos endofíticos isolados (Romano, 2015). Das 3 patentes encontradas, apenas uma está relacionada com o tema do trabalho, onde os inventores verificaram a ação do extrato da $T$. roseoalba frente a patógenos multirresistentes de grande 
importância clínica. A diferença entre a patente e o artigo de Da Silva et al., (2017) é o aperfeiçoamento das técnicas de extração dos compostos bioativos. Mesmo o Brasil tendo tamanha biodiversidade e muitas plantas endêmicas, ao comparar o quantitativo de patentes no WIPO em relação aos países e as palavras-chaves isoladas (Figura 8) observa-se ainda como o Brasil está aquém a se comparar com China, Índia, Estados Unidos da América e diversos outros países que possuem maiores incentivos a pesquisa e ao PD\&I.

Figura 8. Gráfico referente aos países responsável pelo maior quantitativo de patentes no WIPO.

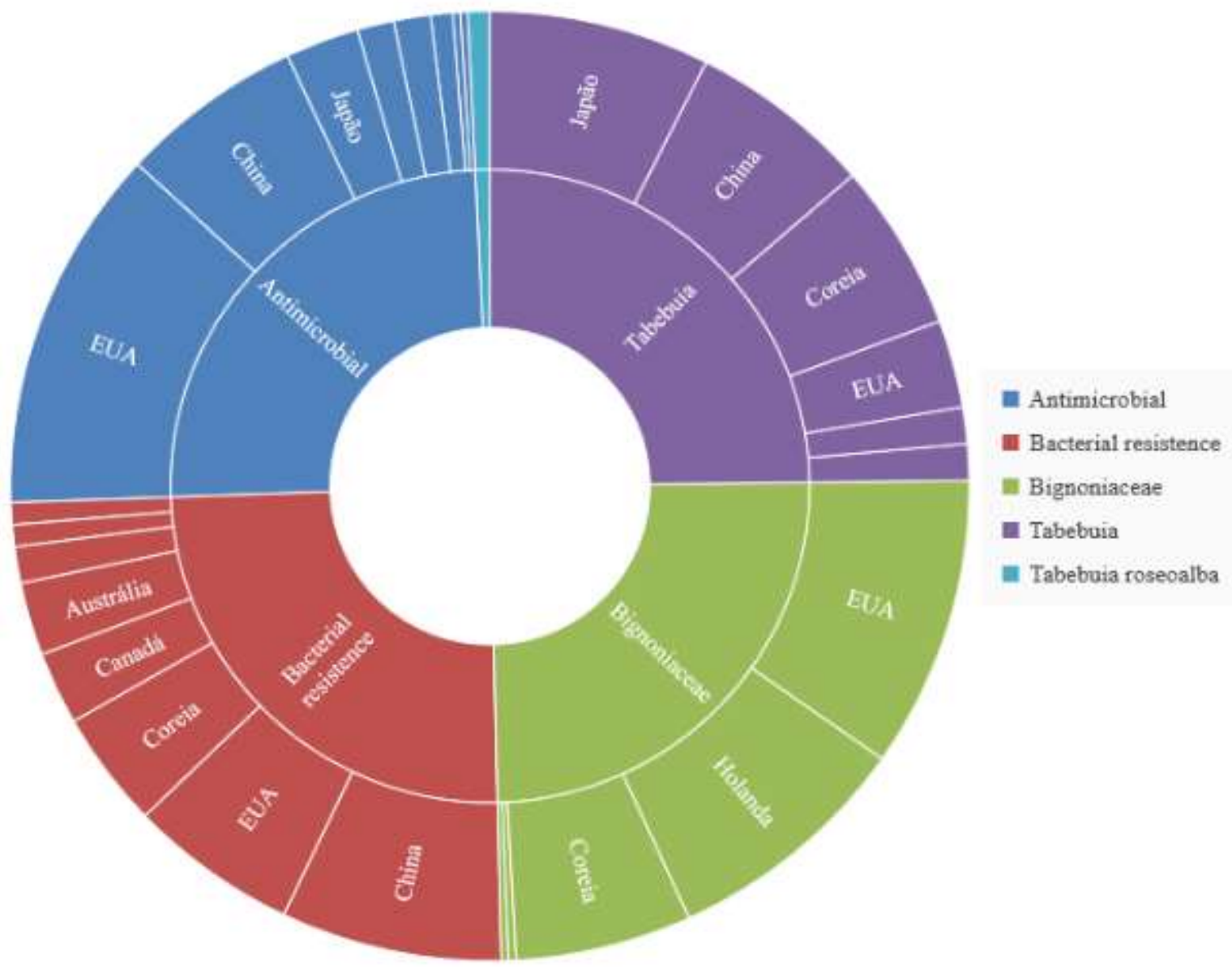

Fonte: Elaborada pelos autores deste artigo, a partir das bases de dados Google Patentes realizadas em 2021.

Além desses incentivos, esses países possuem maior interação entre as Universidades e as Industrias que acabam adquirindo essas invenções e contribuem para a inovação científica e tecnológica. A maioria dos depósitos de patentes brasileiras estão nas mãos das Universidades e a falta de maiores interações entre a indústria faz com que as invenções não passem do papel, e os incentivos privados sejam mais escassos a comparar com os demais países.

\section{Conclusão}

De acordo com os dados obtidos a partir das análises prospectivas, pode-se concluir que há índices crescentes acerca da utilização de extratos naturais plantas, visto que estes disponibilizam alternativas remotas à problemática da resistência bacteriana hoje existente. Como também, foi perceptível que estudos voltados a essa problemática vem ganhando notoriedade pelos riscos à saúde que estes vêm ocasionando. Com isso, visando a resolutividade de tal problema, tem-se estudado, cada vez 
mais, espécies de plantas que, de acordo com a família que pertence, possa oferecer atividades farmacológicas altamente eficiente, a exemplo a Tabebuia roseoalba, espécie pouco estudada, mas que já há evidências de suas atividades farmacológicas frente aos microrganismos patogênicos. Como também, mesmo mediante a escassez de estudos acerca desta espécie, tais resultados só trazem subsídios à continuidade dos estudos voltados, tanto à família Bignoniaceae quanto acerca dos reais potenciais que a Tabebuia roseoalba pode vir a apresentar, havendo assim a necessidades de pesquisas que tenham como objetivo a produção de extratos a fim de se obter conhecimentos sobre novas atividades.

Diante disso, pode-se ressaltar a importância das análises prospectivas como um meio benéfico no qual pode promover a capacidade de organizar a pesquisa inovadora com base nos interesses e necessidades da sociedade. Como também, patentes que adentram como uma fonte de suma importância para avaliar os países e suas respectivas publicações, a fim de identificar quais são os temas que apresentam mais oportunidade e importância para pesquisa e desenvolvimento. Portanto, faz-se necessário estudos mais aprofundados da espécie anteriormente citada, visto que não há muitas referências disponíveis na literatura.

\section{Referências}

Alvarenga, F. Q., Mota, B. C. F., Royo, V. D. A., Laurentiz, R. D. S. D., \& Menezes, E. V. (2016). Atividade antimicrobiana in vitro das folhas de araçá (Psidium cattleianum Sabine) contra micro-organismos da mucosa oral. Revista de Odontologia da UNESP, 45, 149-153.

Amparo, K. K. D. S., Ribeiro, M. D. C. O., \& Guarieiro, L. L. N. (2012). Estudo de caso utilizando mapeamento de prospecção tecnológica como principal ferramenta de busca científica. Perspectivas em Ciência da Informação, 17, 195-209.

Ayhan, D. H., Tamer, Y. T., Akbar, M., Bailey, S. M., Wong, M., Daly, S. M., ... \& Toprak, E. (2016). Sequence-specific targeting of bacterial resistance genes increases antibiotic efficacy. PLoS biology, 14(9), e1002552.

Chaves, J. T., \& Borges, J. D. (2018). Ocorrência de raízes gemíferas em Tabebuia roseoalba (Ridl.) Sandwith (BIGNONIACEAE, LAMIALES). Ciência Florestal, 28, 1789-1797.

Chueke, G. V., \& Amatucci, M. (2015). O que é bibliometria? Uma introdução ao Fórum. Internext, 10(2), 1-5.

Cogen, J. D., Kahl, B. C., Maples, H., McColley, S. A., Roberts, J. A., Winthrop, K. L., ... \& Bell, S. C. (2020). Finding the relevance of antimicrobial stewardship for cystic fibrosis. Journal of Cystic Fibrosis, 19(4), 511-520.

da Silva, J. C., dos Santos, W. B., Araujo, M. G. S., da Silva Oliveira, J. F., Veríssimo, R. C. S. S., Lins, T. H., ... \& de Assis Bastos, M. L. (2017). Evaluation of the Cytotoxic, Antimicrobial and Antioxidant Activity of the Plant Especies Tabebuia roseo-alba (Ridl) Sand. Journal of Chemical and Pharmaceutical Research, 9(4), 148-153.

de Oliveira Lima, S. H., Cândido, L. F., Ibiapina, I., \& Leocádio, Á. L. Inovação e Gestão Pública: Uma Análise da Produção Científica Internacional. Revista Organizações em Contexto, 16(32), 77-94.

El-Hawary, S. S., Taher, M. A., AbouZid, S. F., Amin, E., \& Mohammed, R. (2021). Genus Tabebuia: A comprehensive review journey from past achievements to future perspectives. Arabian Journal of Chemistry, 103046.

Feitosa, M. H. A., Soares, L. L., Borges, G. A., Andrade, M. M., \& Costa, S. D. M. (2016). Inserção do conteúdo fitoterapia em cursos da área de saúde. Revista Brasileira de Educação Médica, 40, 197-203.

Ferraz-Filha, Z. S., Ferrari, F. C., Araújo, M. C. D. P. M., \& Bernardes, A. C. F. P. (2017). Effects of the aqueous extract from Tabebuia roseoalba and phenolic acids on hyperuricemia and inflammation. Evidence-based complementary and alternative medicine, 2017.

Ferraz-Filha, Z. S., Araújo, M. C. D. P. M., Ferrari, F. C., \& Dutra, I. P. A. R. (2016). Tabebuia roseoalba: in vivo hypouricemic and anti-inflammatory effects of its ethanolic extract and constituents. Planta Medica, 82(16), 1395-1402.

Ferreira-Júnior, J. C., Conserva, L. M., Lemos, R. P. L., de Omena-Neta, G. C., Cavalcante-Neto, A., \& Barreto, E. (2015). Isolation of a dihydrobenzofuran lignan, icariside E 4, with an antinociceptive effect from Tabebuia roseo-alba (Ridley) Sandwith (Bignoniaceae) bark. Archives of pharmacal research, 38(6), 950-956.

Gai, A. P. C., dos Santos, D. S., \& Vieira, E. A. (2017). Effects of zinc excess on antioxidant metabolism, mineral content and initial growth of Handroanthus impetiginosus (Mart. ex DC.) Mattos and Tabebuia roseoalba (Ridl.) Sandwith. Environmental and Experimental Botany, 144, 88-99.

Gomes, F., Martins, N., Barros, L., Rodrigues, M. E., Oliveira, M. B. P., Henriques, M., \& Ferreira, I. C. (2018). Plant phenolic extracts as an effective strategy to control Staphylococcus aureus, the dairy industry pathogen. Industrial Crops and Products, 112, 515-520.

Hamed, A. N. E., Mahmoud, B. K., Samy, M. N., \& Kamel, M. S. (2020). An extensive review on genus" Tabebuia", family Bignoniaceae: phytochemistry and biological activities (1967 to 2018). Journal of Herbal Medicine, 100410. 
Hemeg, H. A., Moussa, I. M., Ibrahim, S., Dawoud, T. M., Alhaji, J. H., Mubarak, A. S., ... \& Marouf, S. A. (2020). Antimicrobial effect of different herbal plant extracts against different microbial population. Saudi Journal of Biological Sciences, 27(12), 3221-3227.

Horváth, G., Farkas, Á., Papp, N., Bencsik, T., Ács, K., Gyergyák, K., \& Kocsis, B. (2016). Natural substances from higher plants as potential anti-MRSA agents. Studies in Natural Products Chemistry, 47, 63-110.

Lima, R. A. D., Velho, L. M. L. S., \& Faria, L. I. L. D. (2007). Indicadores bibliométricos de cooperação científica internacional em bioprospecção. Perspectivas em Ciência da Informação, 12, 50-64.

Linzner, N., Fritsch, V. N., Busche, T., Tung, Q. N., Van Loi, V., Bernhardt, J., ... \& Antelmann, H. (2020). The plant-derived naphthoquinone lapachol causes an oxidative stress response in Staphylococcus aureus. Free Radical Biology and Medicine, 158, 126-136.

Malani, P. N. (2014). National burden of invasive methicillin-resistant Staphylococcus aureus infection. Jama, 311(14), 1438-1439.

Mazzei, R., Leonti, M., Spadafora, S., Patitucci, A., \& Tagarelli, G. (2020). A review of the antimicrobial potential of herbal drugs used in popular Italian medicine (1850s-1950s) to treat bacterial skin diseases. Journal of ethnopharmacology, 250, 112443.

Curtinaz Menezes, D., Mota Vieira, D., \& Pereira dos Santos, A. (2020). A TEORIA DOS STAKEHOLDERS NO BRASIL: PRODUÇÃO ACADÊMICA NO PERÍODO DE 2014 A 2019. Revista Ibero-Americana de Estratégia (RIAE), 19(4).

Miller, W. R., Munita, J. M., \& Arias, C. A. (2014). Mechanisms of antibiotic resistance in enterococci. Expert review of anti-infective therapy, 12(10), 12211236.

Neuberger, A., Du, D., \& Luisi, B. F. (2018). Structure and mechanism of bacterial tripartite efflux pumps. Research in microbiology, 169(7-8), 401-413.

Patini, R., Mangino, G., Martellacci, L., Quaranta, G., Masucci, L., \& Gallenzi, P. (2020). The effect of different antibiotic regimens on bacterial resistance: A systematic review. Antibiotics, 9(1), 22.

Prasathkumar, M., Anisha, S., Dhrisya, C., Becky, R., \& Sadhasivam, S. (2021). Therapeutic and pharmacological efficacy of selective Indian medicinal plants-A review. Phytomedicine Plus, 100029.

Pugazhendhi, A., Michael, D., Prakash, D., Krishnamaurthy, P. P., Shanmuganathan, R., Al-Dhabi, N. A., ... \& Kaliannan, T. (2020). Antibiogram and plasmid profiling of beta-lactamase producing multi drug resistant staphylococcus aureus isolated from poultry litter. Journal of King Saud UniversityScience, 32(6), 2723-2727.

Romano, E., Kusio-Kobialka, M., Foukas, P. G., Baumgaertner, P., Meyer, C., Ballabeni, P., ... \& Speiser, D. E. (2015). Ipilimumab-dependent cell-mediated cytotoxicity of regulatory T cells ex vivo by nonclassical monocytes in melanoma patients. Proceedings of the National Academy of Sciences, 112(19), 61406145 .

Romano, L. H. (2014). Bioprospecção de microrganismos endofíticos isolados de Tabebuia spp. e Hymenaea courbaril e identificação da produção de metabólitos de interesse biotecnológico. 